\title{
$17 \beta$-Estradiol reduces inflammation and modulates antioxidant enzymes in colonic epithelial cells
}

\author{
Hee Jin Son ${ }^{1}$, Nayoung Kim ${ }^{2,3}$, Chin-Hee Song ${ }^{2}$, Sun Min Lee ${ }^{2}$, Ha-Na Lee ${ }^{4}$, and Young-Joon Surh ${ }^{4}$
}

\begin{abstract}
${ }^{1}$ Seoul National University College of Medicine, Seoul; ${ }^{2}$ Department of Internal Medicine, Seoul National University Bundang Hospital, Seongnam; ${ }^{3}$ Department of Internal Medicine and Liver Research Institute, Seoul National University College of Medicine, Seoul; ${ }^{4}$ Tumor Microenvironment Global Core Research Center, Seoul National University College of Pharmacy, Seoul, Korea
\end{abstract}

Received: March 11, 2018

Revised : May 31, 2018

Accepted: September 16, 2018

\section{Correspondence to}

Nayoung Kim, M.D.

Department of Internal Medi-

cine, Seoul National University

Bundang Hospital, 82 Gumi-ro

173beon-gil, Bundang-gu,

Seongnam 13620, Korea

Tel: +82-31-787-7008

Fax: + 82-31-787-4051

E-mail: nayoungkim49@empas.com
Background/Aims: Estrogen is known to have protective effect in colorectal cancer development. The aims of this study are to investigate whether estradiol treatment reduces inflammation in $\mathrm{CCD} 841 \mathrm{CoN}$, a female human colonic epithelial cell line and to uncover underlying mechanisms of estradiol effects.

Methods: $17 \beta$-Estradiol (E2) effect was measured by Western blot after inducing inflammation of CCD841CoN by tumor necrosis factor $\alpha$ (TNF- $\alpha$ ). Expression levels of estrogen receptor $\alpha(\mathrm{ER} \alpha)$ and $\beta(\mathrm{ER} \beta)$, cyclooxygenase-2 (COX-2), nuclear

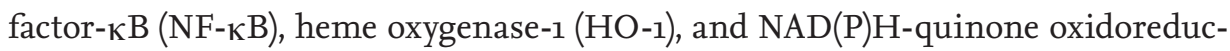
tase-1 (NQO-1) were also evaluated.

Results: E2 treatment induced expression of ER $\beta$ but did not increase that of ER $\alpha$. E2 treatment for 48 hours significantly elevated the expression of anti-oxidant enzymes, HO-1 and NQO-1. TNF- $\alpha$ treatment significantly increased the level of activated NF- $\mathrm{BB}(p<0.05)$, and this increase was significantly suppressed by treatment of $10 \mathrm{nM}$ of E2 $(p<0.05)$. E2 treatment ameliorated TNF- $\alpha$-induced COX-2 expression and decrease of HO-1 expression. 4-(2-phenyl-5,7-bis(trifluoromethyl) pyrazolo(1,5-a)pyrimidin-3-yl)phenol (PHTPP), antagonist of ER $\beta$, removed the inhibitory effect of $\mathrm{E}_{2}$ in the TNF- $\alpha$-induced COX-2 expression $(p=0.05)$.

Conclusions: Estrogen seems to inhibit inflammation in female human colonic epithelial cell lines, through down-regulation of NF- $\mathrm{KB}$ and COX-2 expression and induction of anti-oxidant enzymes such as $\mathrm{HO}-1$ and NQO-1.

Keywords: Estrogens; Estrogen receptor beta; Inflammation; NF-kappa B; Heme oxygenase-1.

\section{INTRODUCTION}

Colorectal cancer (CRC) development is closely related to cancer-related inflammation connected by various pathways such as nuclear factor- $\mathrm{\kappa B}(\mathrm{NF}-\mathrm{\kappa B})$ signaling pathway [1]. Activation of NF- $\kappa B$ modulates production of inflammatory mediators, importantly cyclooxygenase-2 (COX-2) [1]. It is widely accepted that COX-2 has key roles in development of CRC $[2,3]$. For instance,
COX-2 is overexpressed in most CRC tissue [4] and selective inhibition of COX-2 using celecoxib results in prominent prevention of CRC [2].

Previously our team reported that colitis-associated colon tumorigenesis in azoxymethane/dextran sulfate sodium (AOM/DSS) model was induced more severely in male mice than female mice by way of inflammatory mediators such as interleukin $1 \beta$ (IL-1 $\beta$ ) and myeloperoxidase [5]. In addition, we found that $17 \beta$-estradiol (E2; 
$10 \mathrm{mg} / \mathrm{kg}$ ) inhibited the initiation of CRC by upregulating nuclear factor erythroid 2-related factor 2 (NRF2), a transcriptional factor-related pathways in the AOM/ DSS-treated male Institute of Cancer Research mice [6]. Actually, NRF2 induces many genes including anti-oxidant enzymes [7] in breast cancer cell line [8].

Estrogen, especially, biologically active metabolite E2 has extensive roles in carcinogenesis of both reproductive organs (breast, ovary, and uterus) and non-reproductive organs (lung, intestine) [9]. In contrast, many epidemiologic data suggest protective role of estrogen in CRC development [10-12]. These contradictory results could be related that estrogen has two types of receptors, estrogen receptor $\alpha(E R \alpha)$ and $\beta$ (ER $\beta)$ encoded by different genes which have different expression patterns between tissues and organs [13]. Laboratory investigation shows ER $\beta$ is the predominant ER subtype in colon adenocarcinoma cell lines [14]. For instance, in ER $\beta^{-/-}$mice, the differentiation states of colonic epithelial cells are different from that of wild type mice [15]. Furthermore ER $\beta$ is closely related to anti-inflammatory effects of estrogen. Microarray analysis suggests ER $\beta$ selective agonist repressing transcription of inflammatory genes such as tumor necrosis factor $\alpha$ (TNF- $\alpha$ ) and IL-6 in human osteosarcoma cells [16], and estrogen suppressed COX-2 induction by regulating NF- $\mathrm{KB}$ in rat cerebral blood vessels [17].

Heme oxygenase-1 (HO-1) is a key anti-oxidant enzyme that has anti-inflammatory activity and pro-resolving effect [18]. HO-1 inducer treatment results in reduced colonic inflammation and colonic epithelium of patients with inflammatory bowel disease shows dysregulation of HO-1 expression [19]. Regulation of HO-1 expression is related to estrogen that phytoestrogen having structural similarity with E2 upregulates HO-1 [20]. Actually HO-1 has critical role in protective effect of E2 on shock-induced intestinal injury [21]. We also found that pre-treatment of estradiol increased mRNA expression of anti-oxidant enzymes (i.e., HO-1, glutamate-cysteine ligase modifier subunit [GCLM], and $\mathrm{NAD}(\mathrm{P}) \mathrm{H}$-quinone oxidoreductase-1 [NQO-1]) in AOM/DSS treated male mice, suggesting estrogen-NRF2-HO-1 pathway [6]. However, it is not direct experiment regarding estrogen-effect in the inflammation-induced colonic epithelial cells.

Activation of NRF2 leads to the increased expression of $\mathrm{HO}-1$, to inhibit the NF- $\mathrm{KB}$ signalling, which results in the mitigated intestinal mucosa injury and restored tight-junction dysfunction, in male rat liver transplantation model [22]. Kelch-like ECH-assiciated protein-1 (KEAP1), a negative regulator of $\mathrm{NRF} 2$, suppress the transcriptional action of NRF2 under normal conditions [23].

From this background, we hypothesized that estrogen inhibits inflammation and induces antioxidant enzymes through transcriptional regulation by ERs. To assess this hypothesis, we explored modulation of COX-2 and anti-oxygen enzyme expression which was induced by TNF- $\alpha$ and treated by estrogen in colonic epithelial cells.

\section{METHODS}

\section{Cell culture}

The CCD841CoN cells (colonic epithelial cell line originated from female fetus) were kindly provided by Laboratory of Professor Y.J.S. (Tumor Microenvironment Global Core Research Center, Seoul National University College of Pharmacy, Seoul, Korea) and maintained in Minimum Essential Media supplemented with 10\% fetal bovine serum (FBS) and antibiotic-antimycotic mixture (Gibco BRL, Gaithersburg, MD, USA). The cells kept in 10\% charcoal-stripped FBS (CSS) for 24 hours were treated with or without $10 \mathrm{ng} / \mathrm{mL}$ human recombinant TNF- $\alpha$ for 6 hours (210-TA-005, R\&D system, Minneapolis, MI, USA) in the absence or presence of 1, 10, $100 \mathrm{nM}$ water soluble E2 (Sigma E4389, Sigma-Aldrich Co., St. Louis, MO, USA) for 24 or 48 hours. 4-(2-phenyl-5,7-bis(trifluoromethyl)pyrazolo(1,5-a)pyrimidin-3-yl)phenol (PHTPP), an antagonist of ER $\beta$, was treated. All cells were cultured at $37^{\circ} \mathrm{C}$ in a $95 \%$ humidified atmosphere containing $5 \% \mathrm{CO}_{2}$.

\section{Western blot analysis}

After treatment, the media in the apical side was aspirated and the cells were collected by centrifugation at 1,000 rpm for 5 minutes at $4^{\circ} \mathrm{C}$. Cells were suspended in the RIPA cell lysis buffer (Cell Signaling Technology, Beverly, MA, USA) with protease and phosphatase inhibitors and kept on ice for 20 minutes. After centrifugation at 13,000 rpm for 15 minutes, the supernatant was collected and stored at $-70^{\circ} \mathrm{C}$ until use.

Whole cell extracts were isolated using RIPA buffer 
Table 1. List of antibodies and its characteristic

\begin{tabular}{|c|c|c|}
\hline Antigen & Antibody & Experimental conditions \\
\hline $\mathrm{COX}-2$ & Santa Cruz Biotechnology (sc1745) & WB $(1: 1,000)$ \\
\hline $\mathrm{NF}-\kappa \mathrm{B}$ p 65 & Santa Cruz Biotechnology (sc8oo8) & WB $(1: 1,000)$ \\
\hline $\mathrm{HO}-1$ & Abcam $(a b 13248)$ & WB (1:1,000) \\
\hline NQO1 & Abcam (ab34173) & WB $(1: 5,000)$ \\
\hline $\mathrm{ER} \alpha$ & Abcam (ab93021) & WB (1:1,000) \\
\hline $\mathrm{ER} \beta$ & Abcam $\left(\mathrm{ab}_{3576)}\right.$ & WB (1:1,000) \\
\hline$\beta$-Actin & Santa Cruz Biotechnology (sc47778) & WB $(1: 4,000)$ \\
\hline Lamin B & Santa Cruz Biotechnology (sc6216) & WB $(1: 4,000)$ \\
\hline
\end{tabular}

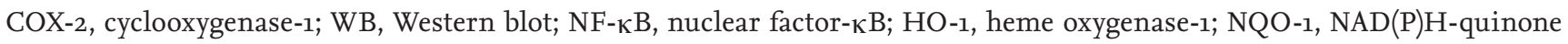
oxidoreductase-1; ER $\alpha$, estrogen receptor $\alpha$; ER $\beta$, estrogen receptor $\beta$.

with protease and phosphatase inhibitors. Cytoplasmic and nuclear lysates were separated using a NE-PER Nuclear Cytoplasmic Extraction Reagent kit (Pierce, Rockford, IL, USA) according to the manufacturer's instructions. Protein concentration was determined using the bicinchoninic acid (BCA) protein assay reagent (Pierce). Protein samples were mixed with an equal volume of $5 \times$ sodium dodecyl sulfate (SDS) sample buffer, boiled for 5 minutes, and then separated using $8 \%$ to $15 \%$ SDS-polyacrylamide gel electrophoresis (PAGE). After electrophoresis, proteins were transferred to polyvinylidene difluoride (PVDF) membranes. The membranes were blocked with $5 \%$ nonfat dry milk in Tris-buffered saline with Tween-20 buffer (TBS-T) for 1 hour at room temperature. Membranes were incubated overnight at $4^{\circ} \mathrm{C}$ with specific antibodies. Primary antibodies were removed by washing the membranes three times in TBS-T, and incubated for 2 hours with horseradish peroxidase-conjugated anti-rabbit, anti-goat, or anti-mouse immunoglobulin (Santa Cruz Biotechnology, Dallas, TX, USA). Following three washes with TBS-T, antigen-antibody complexes were detected using the SuperSignal West Pico Chemiluminescence System (Thermo Fisher Scientific, Rockford, IL, USA). The antibodies are listed in detail in the Table 1.

\section{Quantitative real-time polymerase chain reaction}

The CCD841CoN cells kept in 10\% CSS for 24 hours were treated with or without $10 \mathrm{ng} / \mathrm{mL}$ human recombinant TNF- $\alpha$ for 6 hours in the absence or presence of $10 \mathrm{nM}$ E2 for 48 hours. Total RNA was prepared from the cells using Trizol reagent (Invitrogen, Carlsbad, CA, USA) according to the manufacturer's instruments, and quantified using a NanoDrop ND-10oo device (Thermo Scientific, Wilmington, DE, USA). Complementary DNA (cDNA) was synthesized using the High Capacity cDNA reverse Transcription Kit (Applied Biosystems, Foster City, CA, USA). The cDNA was used to perform quantitative real-time polymerase chain reaction (qRT-PCR) using specific primers (listed in Table 2) and Power SYBR Green PCR Master mix (Thermo Fisher Scientific, Waltham, MA, USA) in Viia7 instrument (Applied Biosystems). Expression levels of the genes were normalized to that of glyceraldehyde 3-phosphate dehydrogenase.

\section{Statistical analyses}

Data are expressed as mean \pm SEM. Statistical significance was examined with Mann-Whitney test or Fisher's exact test. A $p<0.05$ was considered to indicate a statistical significance. All statistical analyses were conducted using SPSS version 18.0 (SPSS Inc., Chicago, IL, USA) and GraphPad Prism software (GraphPad, La Jolla, CA, USA).

\section{RESULTS}

E2 treatment increases ER $\beta$ expression and induces anti-oxidant enzymes in colonic epithelial cells

First of all ER expression patterns were investigated in CCD841CoN depending on E2 treatment time (24-, 48hour) and concentration $(1,10,100 \mathrm{nM})$ using Western 
Table 2. List of oligonucleotides for quantitative real-time polymerase chain reaction

\begin{tabular}{|c|c|}
\hline Gene & Sequence $\left(5^{\prime} \rightarrow 3^{\prime}\right)$ \\
\hline $\mathrm{HO}-1$ & $\begin{array}{l}\text { F: ATG GCC TCC CTG TAC CAC ATC } \\
\text { R: TGT TGC GCT CAA TCT CCT CCT }\end{array}$ \\
\hline NQO-1 & $\begin{array}{l}\text { F: CGC AGA CCT TGT GAT AT'T CCA G } \\
\text { R: CGT TTC TTC CAT CCT TCC AGG }\end{array}$ \\
\hline NRF2 & $\begin{array}{l}\text { F: TGC CCC TGG AAG TGT CAA ACA } \\
\text { R: CAA CAG GGA GGT TAA TGA TT'T }\end{array}$ \\
\hline KEAPı & $\begin{array}{l}\text { F: CAG ATT GGC TGT GTG GAG T'T } \\
\text { R: GCT GT'T CGC AGT CGT ACT TG }\end{array}$ \\
\hline GAPDH & $\begin{array}{l}\text { F: TTC ACC ACC ATG GAG AAG GC } \\
\text { R: GGC ATG GAC TGT GGT CAT GA }\end{array}$ \\
\hline
\end{tabular}

HO-1, heme oxygenase-1; NQO-1, NAD(P)H-quinone oxidoreductase-1; NRF2, nuclear factor erythroid 2-related factor 2; KEAP1, Kelch-like ECH-associated protein 1; GAPDH, glyceraldehyde-3-phosphate dehydrogenase.

blot analysis. ER $\alpha$ expression has no significant change after E2 treatment (Fig. 1A). In contrast 48 hours of E2 treatment consistently increased ER $\beta$ expression from 1 $\mathrm{nM}$ concentration of $\mathrm{E}_{2}(p<0.05)$ (Fig. 1B).

In the next anti-oxidant enzyme expressions were measured following E2 treatment by Western blot analysis. Low basal level expression of HO-1 showed concentration-dependent increment of expression after 48 hours E2 treatment $(p<0.05)$ (Fig. $1 \mathrm{C}$ ). NQO-1, another antioxidant enzyme, also increased after 48 hours E2 treatment although it is not prominent as HO-1 due to high basal level expression $(p<0.05$ ) (Fig. 1D). Strangely the expression of NQO-1 decreased by 24 hours incubation of E2 $(p<0.05)$ (Fig. 1D).

Forty-eight hours E2 treatment with $10 \mathrm{nM}$ concentration showed the most stable expression of ER $\beta$ and antioxidant enzymes, HO-1 and NQO-1 (Fig. 1E). Therefore, we further performed experiment with 48 hours of $10 \mathrm{nM}$ E2 treatment.

\section{E2 treatment inhibits NF- $\kappa B$ pathway and increases HO-1 expression following TNF- $\alpha$ induced inflam- mation}

To mimic inflammatory environment colonic epithelial cells were treated with TNF- $\alpha$ (10 ng/mL) for 6 hours just after 18-hour treatment of E2 (Fig. 2A). ER $\beta$ expression level increased when both $10 \mathrm{nM}$ E2 and $10 \mathrm{ng} / \mathrm{mL}$
TNF- $\alpha$ were administrated while TNF- $\alpha$ treatment alone did not show any significant change of ER $\beta$ expression (Fig. 2B). Next, we measured severity of inflammation by NF- $\mathrm{KB}$ and COX-2 expression levels. TNF- $\alpha$ treatment for 10 to 20 minutes significantly increased the level of activated NF- $\kappa \mathrm{B}(p<0.05)$, and this increase was significantly suppressed in the cells by treatment of $10 \mathrm{nM}$ of $\mathrm{E} 2(p<0.05)$. In contrast, $10 \mathrm{ng} / \mathrm{mL}$ TNF- $\alpha$ treatment induced high level of COX-2 expression $(p<0.001)$ while E2 treatment attenuated the increased level of COX-2 $(p<0.05$ ) (Fig. 2D). HO-1, a representative antioxidant enzyme, decreased its expression by $10 \mathrm{ng} / \mathrm{mL}$ TNF- $\alpha$ treatment $(p<0.05)$. However, the pretreatment of $10 \mathrm{nM}$ E2 prevented TNF- $\alpha$-induced decrease of HO-1 expression $(p<0.01)$ (Fig. 2 E). Furthermore pretreatment of 10 $\mathrm{nM}$ E2 further increased HO-1 level similar to that of $10 \mathrm{nM}$ E2 treatment alone, which was very higher than the control $(p<0.001$ ) (Fig. $2 \mathrm{E}$ ). As shown in Fig. $2 \mathrm{~F}$, the protein expression of COX-2 was significantly increased with TNF- $\alpha(p<0.05)$. Again this increase was inhibited by E2 $(p=0.05)$, and the effect of E2 vanished by PHTPP $(p=0.05)$.

The mRNA expression of HO-1 was significantly decreased with either TNF- $\alpha$ or E2 $(p<0.05)$ (Fig. 2 G). The increase of HO-1 mRNA expression by E2 was not statistically significant $(p>0.05)$. Similarly, the mRNA expression of NQO-1 was significantly reduced with either TNF- $\alpha$ or E2 $(p<0.05)$ (Fig. $2 \mathrm{H})$. However, E2 did not significantly recover the level of NQO-1 mRNA level ( $p$ $>0.05$ ).

\section{Influence of E2 on the TNF- $\alpha$-induced expression of KEAP1 and NRF2}

The protein expression level of KEAP1 showed no significant difference according to the treatment of TNF- $\alpha$ and E2 (Fig. 3A). The protein expression level of NRF2 seemed to increase when the $10 \mathrm{ng} / \mathrm{mL}$ TNF- $\alpha$ was treated for 6 hours. E2 the NRF2 protein expression when it was treated for 2 to 3 hours. At 6 hours, the NRF2 protein level decreased with E2.

After treatment of TNF- $\alpha$ and/or E2 for 6 hours, the mRNA expression of KEAP1 was significantly diminished by either TNF- $\alpha$ or E2, respectively $(p<0.05)$ (Fig. $\left.{ }_{3} \mathrm{~B}\right)$. However, the increase of KEAP1 mRNA level by E2 was not statistically significant $(p>0.05)$. The mRNA expression of NRF2 was significantly increased with 

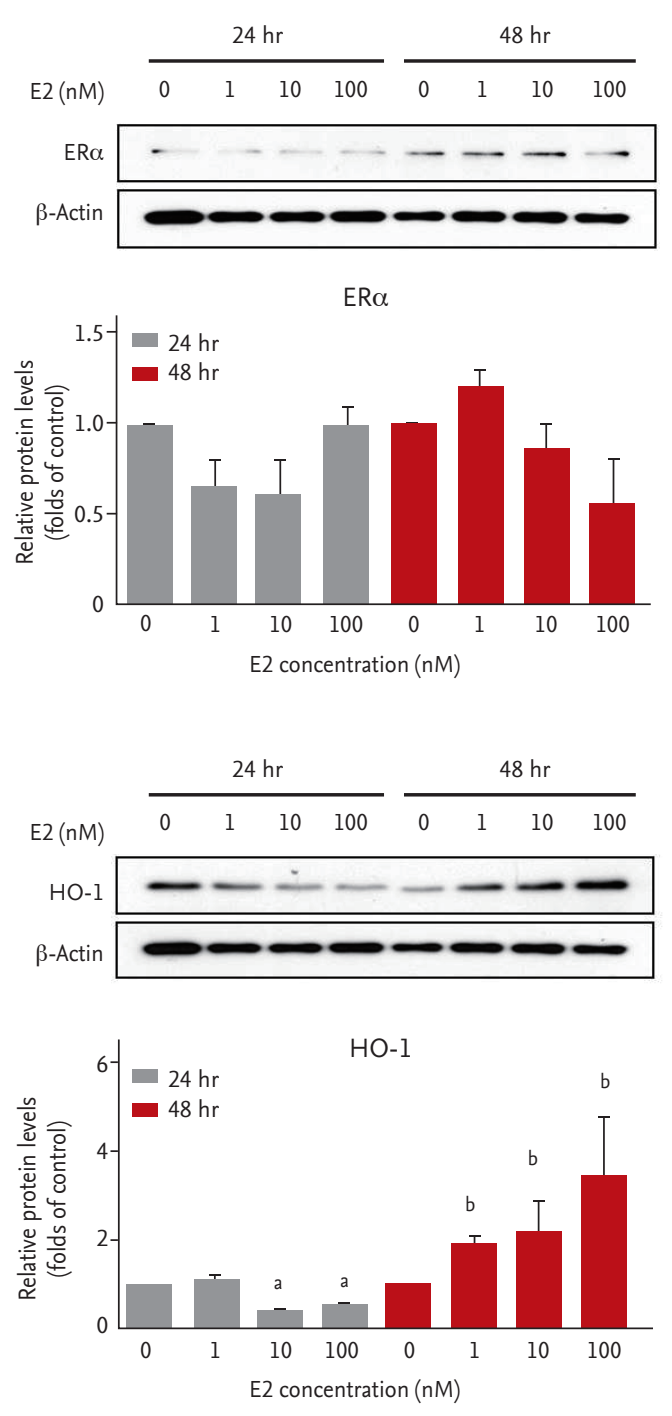

C

E

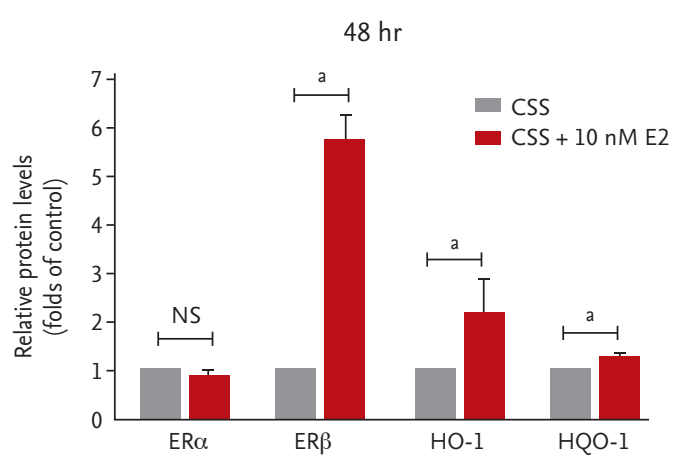

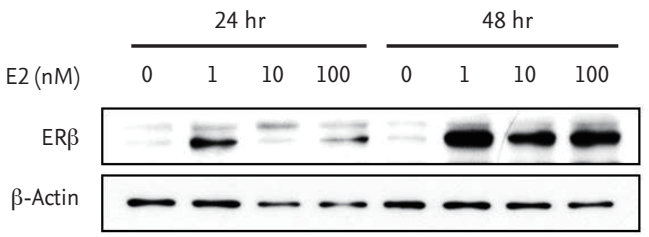

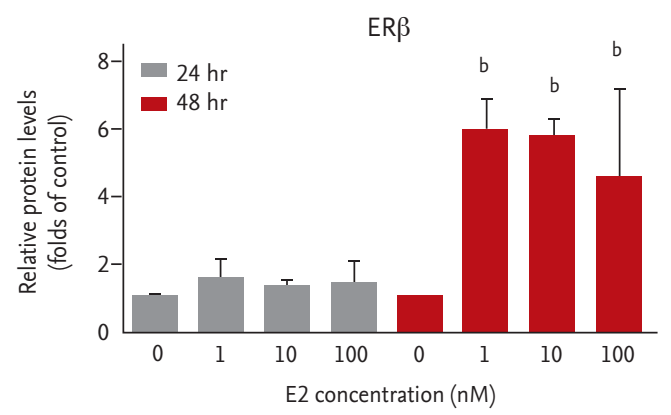

B
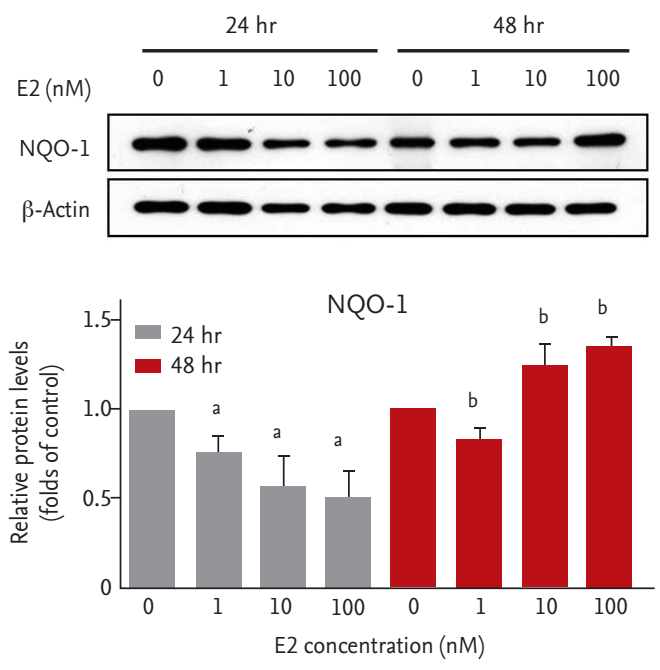

D

Figure 1. 17 $\beta$-Estradiol (E2) treatment increases estrogen receptor $\beta$ (ER $\beta)$ expression and induces anti-oxidant enzymes in colonic epithelial cells. E2 in various concentrations (1, 10, $100 \mathrm{nM})$ and hours (24, 48 hours) did not show difference in estrogen receptor $\alpha(\mathrm{ER} \alpha)$ expression measure by Western blot analysis (A) while ER $\beta$ increases its expression when 1 , 10, or $100 \mathrm{nM}$ of E2 was treated for 48 hours (B). (C) Heme oxygenase-1 (HO-1) has concentration-dependent increment of expression after 48 hours of E2 treatment. (D) NAD(P) $\mathrm{H}$-quinone oxidoreductase-1 (NQO-1) also increases after 48 hours of E2 treatment. (E) Comparison between ERs and antioxidant enzymes, $\mathrm{HO}-1$ and NQO1 expression level treated with $10 \mathrm{nM}$ of E2 for 48 hours. CSS, charcoal-stripped fetal bovine serum; NS, not significant. ${ }^{a} p<0.05$ compared with the control (o, white bar) of target gene expression, ${ }^{b} p<0.05$ compared with the control (o, black bar) of target gene expression. 
A
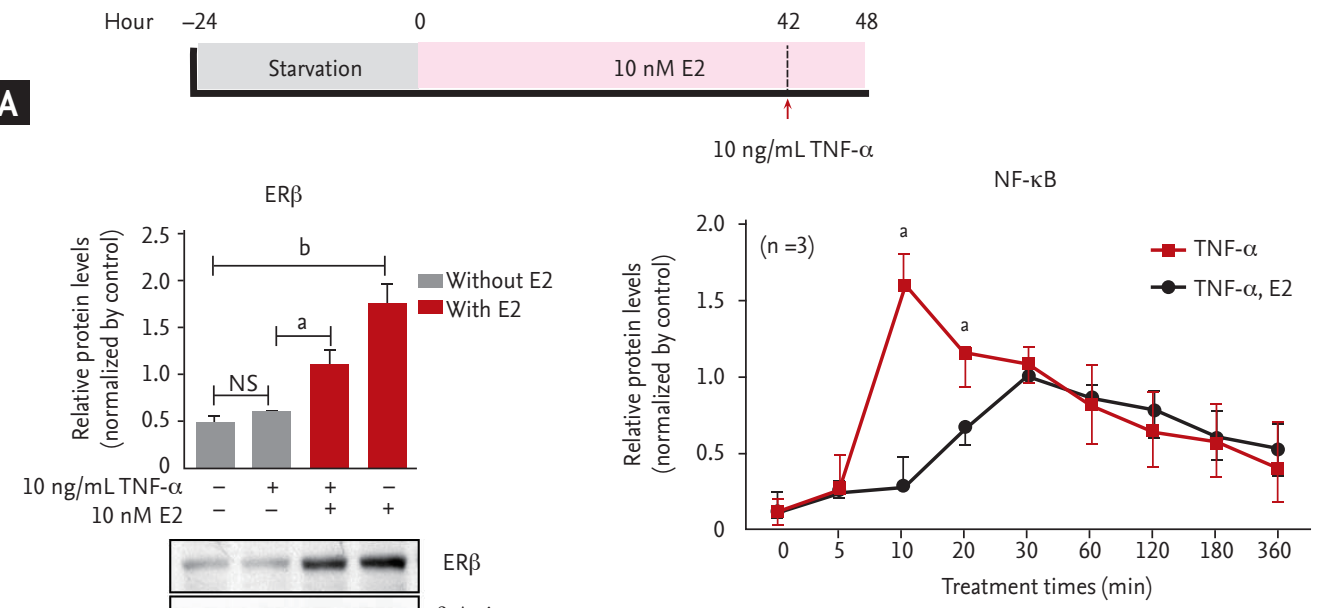

B
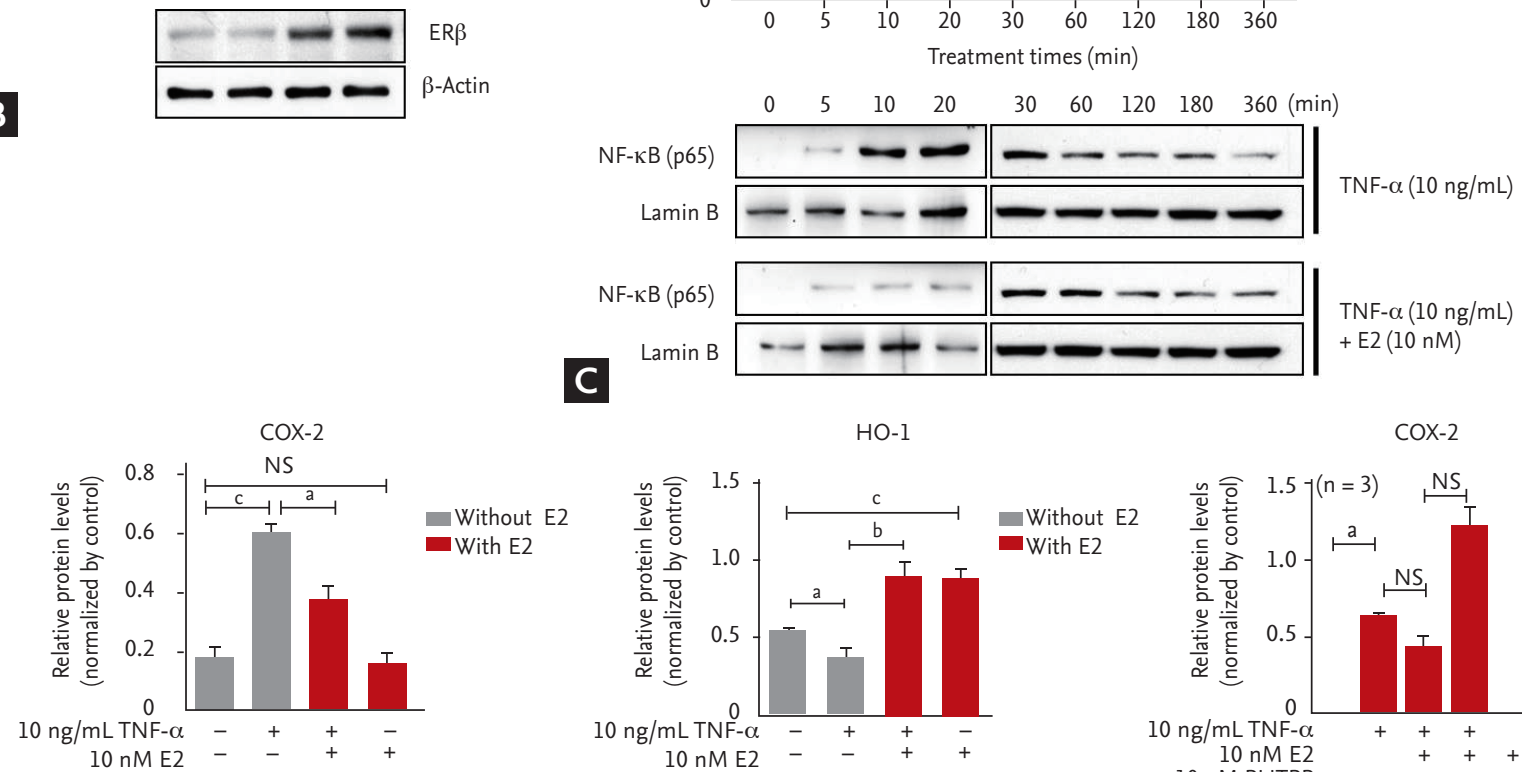

D
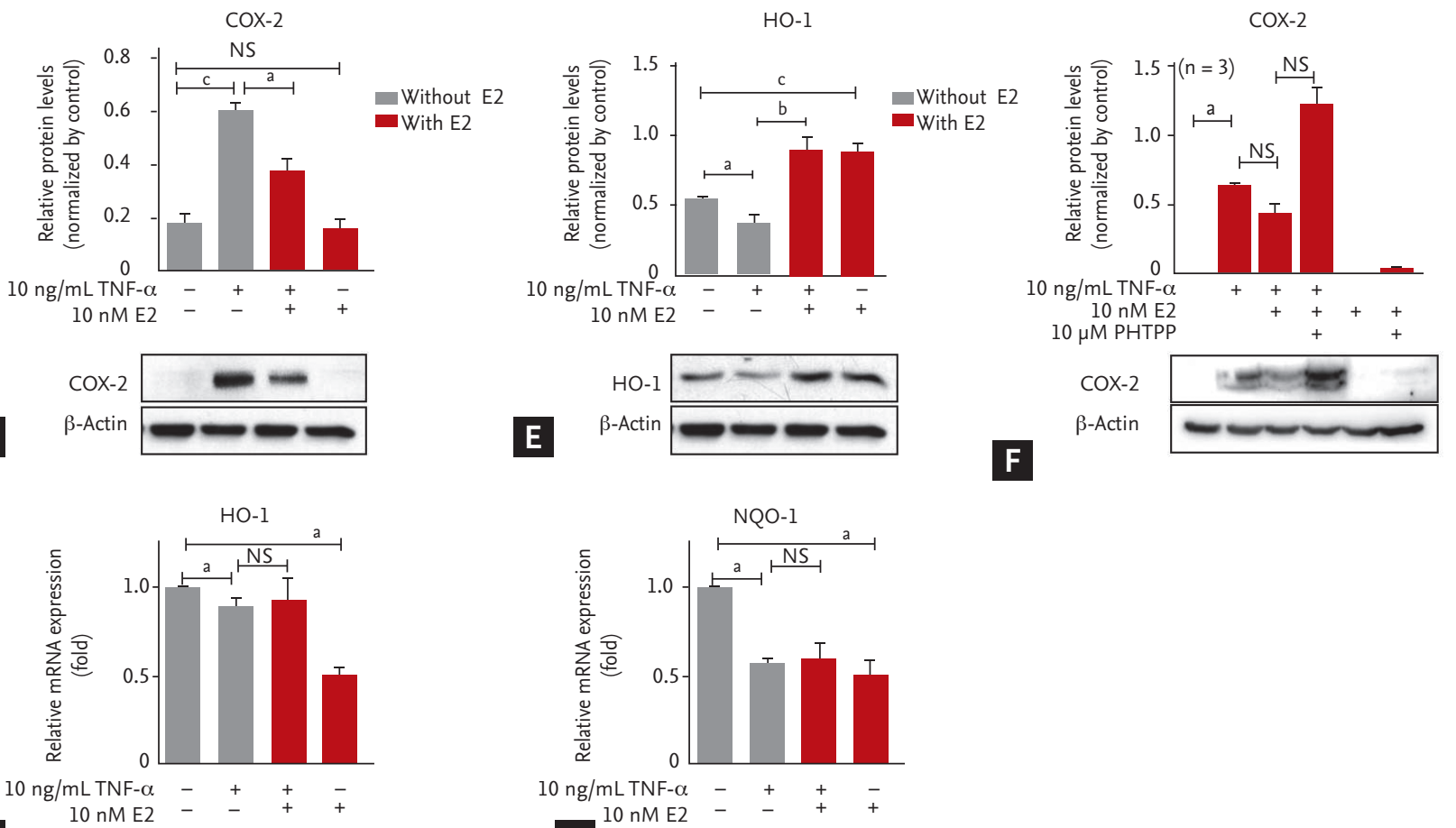

G

$10 \mathrm{nM}$ E2

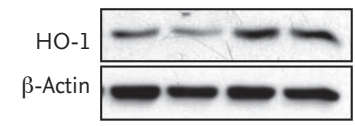

$\mathbf{E}$

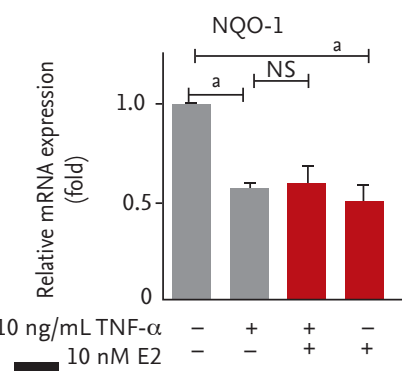

Figure 2. $17 \beta$-Estradiol (E2) treatment inhibits nuclear factor- $\kappa \mathrm{B}(\mathrm{NF}-\kappa \mathrm{B})$ pathway and increases heme oxygenase-1 $(\mathrm{HO}-1)$ expression following tumor necrosis factor $\alpha$ (TNF- $\alpha$ ) induced inflammation. (A) Scheme for experimental courses to evaluate effects of E2 when TNF- $\alpha$ induces inflammation. (B) Estrogen receptor $\beta$ (ER $\beta$ ) expression level analyzed by Western blot analysis increases when both $\mathrm{E} 2$ and TNF- $\alpha$ are administrated. (C) The time-dependent protein expression level of NF- $\kappa \mathrm{B}$ during the treatment of TNF- $\alpha$ and TNF- $\alpha+$ E2 for 360 minutes. (D) TNF- $\alpha$ treatment induces high level of cyclooxygenase-2 (COX-2) expression and E2 treatment does not show significant difference of the level. (E) HO-1 increases its expression when both E2 and TNF- $\alpha$ were administered compared to the group only TNF- $\alpha$ was treated. (F) An antagonist of ER $\beta$, 4-(2-phenyl-5,7-bis(trifluoromethyl)pyrazolo(1,5-a)pyrimidin-3-yl)phenol (PHTPP), removed the inhibitory effect of E2 in the TNF- $\alpha$ induced increase of COX-2 expression. $(\mathrm{G}, \mathrm{H})$ The mRNA expression of antioxidants (HO-1 and NQO-1). NS, not significant. ${ }^{a} p$ $<0.05,{ }^{b} p<0.01,{ }^{c} p<0.001$. 

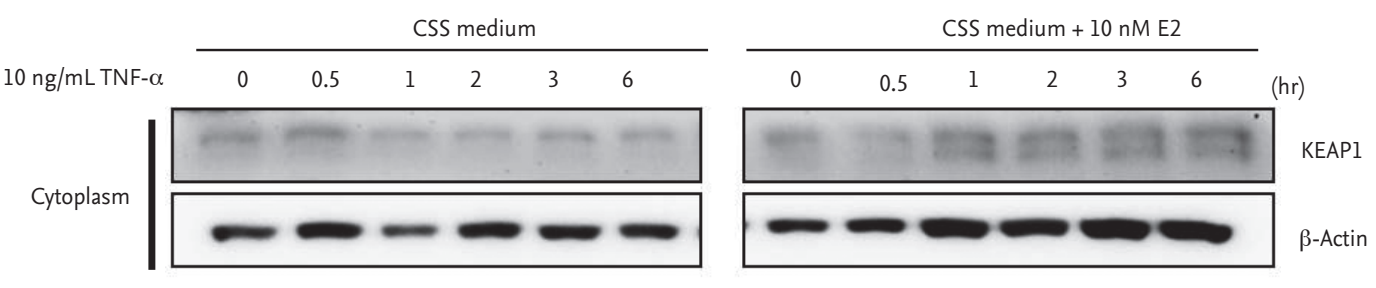

A
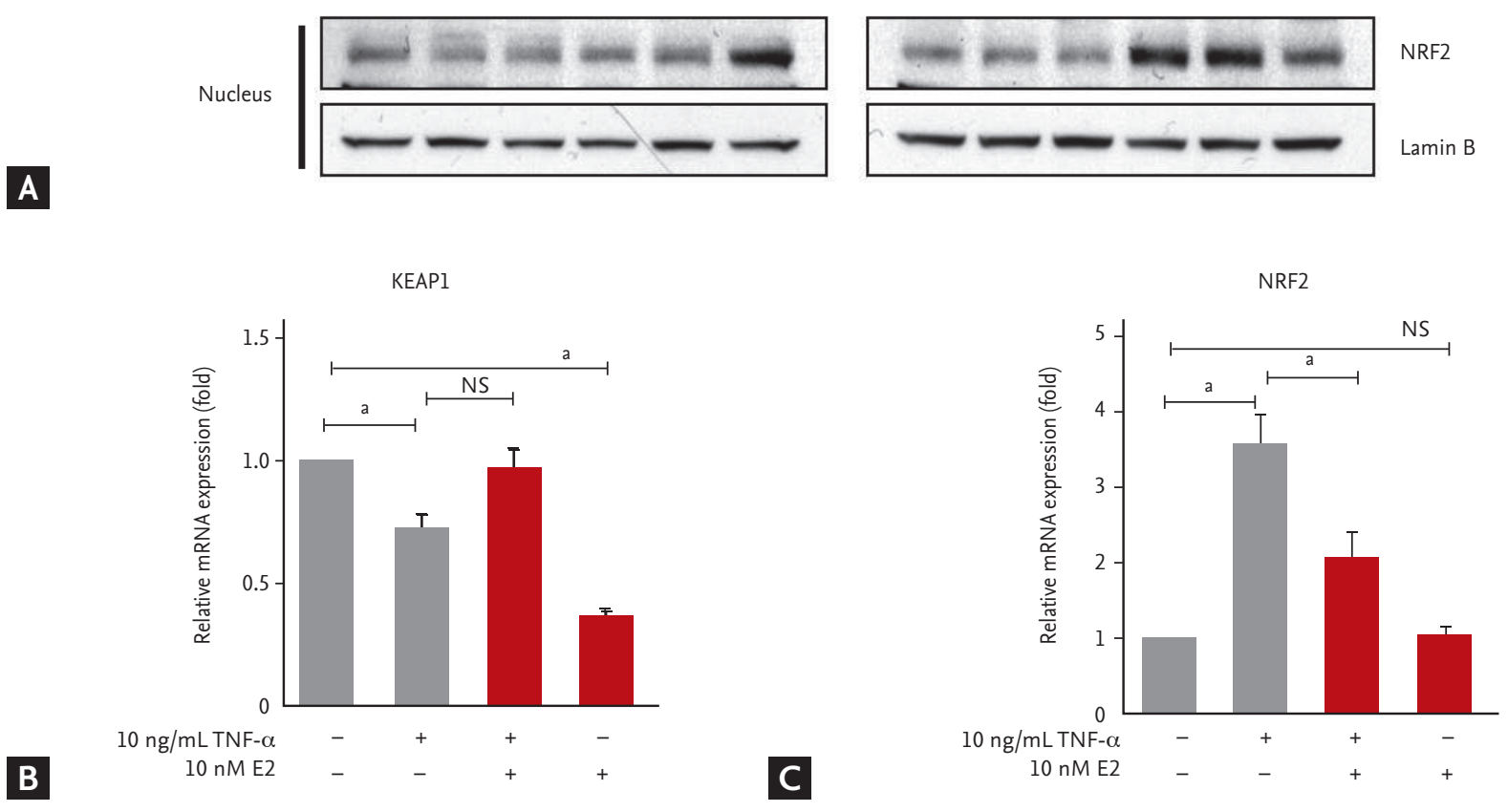

Figure 3. The expression levels of Kelch-like ECH-assiciated protein-1 (KEAP1) and nuclear factor erythroid 2-related factor 2 $(\mathrm{NRF} 2)$ in colonic epithelial cell lines, treated with tumor necrosis factor $\alpha$ (TNF- $\alpha$ ) and/or 17 $\beta$-estradiol (E2). (A) Protein expression level of KEAP1 and NRF2, during o to 6 hours of treatment. The mRNA expression levels of KEAP1 (B) and NRF2 (C) at 6 hours after treatment of TNF- $\alpha$ and/or E2. NS, not significant. ${ }^{a} p<0.05$.

TNF- $\alpha(p<0.05)$, and it was reduced by E2 $(p<0.05)$ (Fig. 3C).

\section{DISCUSSION}

As demonstrated in our previous report, sex differences occur in CRC development by showing lower tumor multiplicity and lower incidence in AOM/DSS-treated female mice compared with AOM/DSS-treated male mice [5]. When we further investigated the underlying anti-cancer mechanism of estrogen it suggested important roles of NF- $\mathrm{KB}$ inflammatory signaling pathway and anti-oxidant enzymes in cancer-related inflammation and carcinogenesis in vivo system [6]. However, the results were rather complicated mainly because in vivo animal reflects multi-signal condition system [6]. The cell line in vivo system might be more clear and straight forward to reveal sex-specific medicine in CRC. Recently, National Institutes of Health (NIH) announced that grant applicants must consider the sex of animals and cells in study design, and it is being encouraged to monitor sex of cells in preclinical studies [24]. Therefore, in the present study, we used female human cell lines, reflecting the recent encourage about considering sex differences in cell line experiments. The present study shows that E2 treatment reduces COX-2 expression and increases the anti-oxidant enzyme, i.e., HO-1 expression possibly mediated by ER $\beta$, which have not been shown in previous studies to our knowledge.

The NF-kB signaling pathway is very involved in inflammation and cancer development, especially in 
colitis-associated CRC [25]. In the present study, E2 treatment inhibited COX-2 expression as well as NF$\kappa \mathrm{B}$ activation during TNF- $\alpha$-induced inflammation in the colonic epithelial cell line. However, inhibition of NF- $\mathrm{BB}$ by E2 appeared only in the early period of E2 treatment (Fig. 2C). This consistent response to E2 treatment of both NF- $\mathrm{KB}$ and COX-2 suggests that E2 might control COX-2 through inhibition of NF-кB. However, tissue-specific modulation of COX-2 expression in the uterus and the vena cava by estrogen showed complicated nature of COX-2 modulation [26]. In addition, there was a report in colorectal cell lines, which showed positive and negative regulation of NF- $\mathrm{KB}$ by COX-2 by different prostaglandins [27]. Thus more experiments are needed for clarification of this relationship between NF- $\mathrm{BB}$ and COX-2 in terms of estrogen. The inhibitory effect of E2 on COX-2 expression is further evidenced by the increase of COX-2 expression in the colonic cell line treated with TNF- $\alpha$, and disappearance of E2-induced decrease effect by PHT'PP, an antagonist of ER $\beta$.

It has been reported that anti-oxidant enzymes activated by NRF2 have cancer preventive effects by eliminating reactive oxygen species [28] and facilitating the resolution of inflammation [18]. In the present study, the levels of HO-1 expression were different between control and E2 treated cells, implicating the NRF2-related anti-oxidant reaction as an underlying mechanism of the protective effect of estrogen. These results are in accordance with the increased susceptibility to DSS-induced colitis and colitis-associated colon cancer in NRF2 knockout mice [29,30]. We clearly showed that prevention of TNF- $\alpha$-induced decrease of $\mathrm{HO}-1$ expression by E2 pretreatment $(p<0.01)$, and E2 furthermore increased the level of HO-1 expression similar to that of $10 \mathrm{nM}$ E2 treatment alone, which was very higher than the control $(p<0.001)$. It means that E2 stimulation of HO-1 becomes very strong when the cell line is attacked by inflammatory condition by such as TNF- $\alpha$. Probably it is related with characteristics of $\mathrm{CCD} 841 \mathrm{CoN}$ originated from female fetus. There has been interesting report that 11-oxidoreductase activity and basal and cortisoneor cortisol-stimulated fibroblast-pneumonocyte factor activity has been significantly higher in the female than male fibroblast cell line which has been established from 19 days' gestation rat fetal lung [31]. These differences would lead to a sex difference in the synthesis of pulmonary surfactant [31]. In addition, it was reported that gender dissimilarity appears in radiosensitivity as measured in 152 fibroblast cell cultures obtained from normal individuals [32]. Thus it would be interesting if comparison experiment is performed in male originated colon cancer cell line in addition to female originated cell line, CCD841CoN. Actually this is the limitation of our study. Furthermore, we could not get consistent expression results between mRNA and protein of anti-oxidant enzymes such as HO- 1 and NQO1. According to previous report, the expression correlation between mRNA and protein can be as little as $40 \%$ depending on the system, and there are many processes between transcription and translation [33]. Actually, we focused on the time that the E2 treatment regulated the protein expressions on CCD841CoN cells. To investigate the expression correlation, it is necessary to perform further mechanistic studies on E2 treatment time series.

$\mathrm{KEAP} / \mathrm{NRF} 2$ signalling pathway regulates anti-inflammatory gene expression to suppress the progression of inflammation [22]. The upregulation of NRF2 by E2 during 2 to 3 hours after treatment is consistent with a previous study that reported the stimulation of NRF2-KEAP1 antioxidant defense in human neuroblast cell line [34]. The persistent expression of KEAP1 with little variation during TNF- $\alpha / E 2$ treatment was in accordance with previous results [35]. According to the mRNA and protein expression levels of $\mathrm{NRF}_{2}$ (Fig. $3 \mathrm{~A}$ and ${ }_{3} \mathrm{C}$ ), E2 might promote the expression of $\mathrm{NRF}_{2}$ during 2 to 3 hours after treatment, and then inhibit the NRF2 expression at 6 hours, in CCD841CoN.

In conclusion, estrogen seems to inhibit inflammation in female human colonic epithelial cell lines, through down-regulation of NF- $\mathrm{KB}$ and COX-2 expression and induction of anti-oxidant enzymes such as $\mathrm{HO}_{-1}$ and NQO-1.

\section{KEY MESSAGE}

1. In colonic epithelial cell line originated from female fetus, $17 \beta$-estradiol (E2) treatment induced expression of estrogen receptor $\beta$, increased the expression of anti-oxidant enzymes including heme oxygenase-1 (HO-1) and $\mathrm{NAD}(\mathrm{P}) \mathrm{H}$-quinone oxidoreductase-1. After tumor necrosis 
factor $\alpha$ treatment, E2 treatment reduced nuclear factor- $\mathrm{B}(\mathrm{NF}-\kappa \mathrm{B})$, cyclooxygenase-2 (COX-2) expression and increased $\mathrm{HO}-1$ expression.

2. These results suggest that inhibition of NF- $\kappa B$, COX-2 expression and induction of antioxidant enzymes may be possible mechanisms of inhibition of cancer-related inflammation by E2 in in vitro system.

\section{Conflict of interest}

No potential conflict of interest relevant to this article was reported.

\section{Acknowledgments}

This work was supported by a grant from the National Research Foundation of Korea (NRF) funded by the government of the Republic of Korea (2016R1A2B4013133).

\section{REFERENCES}

1. Mantovani A, Allavena P, Sica A, Balkwill F. Cancer-related inflammation. Nature 2008;454:436-444.

2. Koehne CH, Dubois RN. COX-2 inhibition and colorectal cancer. Semin Oncol 2004;31(2 Suppl 7):12-21.

3. Chan AT, Ogino S, Fuchs CS. Aspirin and the risk of colorectal cancer in relation to the expression of COX-2. N Engl J Med 2007;356:2131-2142.

4. Wang D, Dubois RN. The role of COX-2 in intestinal inflammation and colorectal cancer. Oncogene 2010;29:781788.

5. Lee SM, Kim N, Son HJ, et al. The effect of sex on the azoxymethane/dextran sulfate sodium-treated mice model of colon cancer. J Cancer Prev 2016;21:271-278.

6. Son HJ, Sohn SH, Kim N, et al. Effect of estradiol in an azoxymethane/dextran sulfate sodium-treated mouse model of colorectal cancer: implication for sex difference in colorectal cancer development. Cancer Res Treat 2019;51:632-648.

7. Niture SK, Khatri R, Jaiswal AK. Regulation of Nrf2: an update. Free Radic Biol Med 2014;66:36-44.

8. Wu J, Williams D, Walter GA, Thompson WE, Sidell N. Estrogen increases Nrf2 activity through activation of the $\mathrm{PI}_{3} \mathrm{~K}$ pathway in MCF-7 breast cancer cells. Exp Cell Res
2014;328:351-360.

9. Caiazza F, Ryan EJ, Doherty G, Winter DC, Sheahan K. Estrogen receptors and their implications in colorectal carcinogenesis. Front Oncol 2015;5:19.

10. Gierisch JM, Coeytaux RR, Urrutia RP, et al. Oral contraceptive use and risk of breast, cervical, colorectal, and endometrial cancers: a systematic review. Cancer Epidemiol Biomarkers Prev 2013;22:1931-1943.

11. Chlebowski RT, Wactawski-Wende J, Ritenbaugh C, et al. Estrogen plus progestin and colorectal cancer in postmenopausal women. N Engl J Med 2004;350:991-1004.

12. Kim SE, Paik HY, Yoon H, Lee JE, Kim N, Sung MK. Sexand gender-specific disparities in colorectal cancer risk. World J Gastroenterol 2015;21:5167-5175.

13. Kuiper GG, Carlsson B, Grandien K, et al. Comparison of the ligand binding specificity and transcript tissue distribution of estrogen receptors alpha and beta. Endocrinology 1997;138:863-870.

14. Campbell-Thompson M, Lynch IJ, Bhardwaj B. Expression of estrogen receptor (ER) subtypes and ERbeta isoforms in colon cancer. Cancer Res 2001;61:632-640.

15. Wada-Hiraike O, Imamov O, Hiraike H, et al. Role of estrogen receptor beta in colonic epithelium. Proc Natl Acad Sci U S A 2006;103:2959-2964.

16. Cvoro A, Tatomer D, Tee MK, Zogovic T, Harris HA, Leitman DC. Selective estrogen receptor-beta agonists repress transcription of proinflammatory genes. J Immunol 2008;180:630-636.

17. Ospina JA, Brevig HN, Krause DN, Duckles SP. Estrogen suppresses IL-1beta-mediated induction of COX-2 pathway in rat cerebral blood vessels. Am J Physiol Heart Circ Physiol 2004;286:H2O10-H2O19.

18. Kim W, Lee HN, Jang JH, et al. 15-Deoxy-delta(12,14)-prostaglandin J2 exerts proresolving effects through nuclear factor E2-related factor 2-induced expression of $\mathrm{CD}_{3} 6$ and heme oxygenase-1. Antioxid Redox Signal 2017;27:1412-1431.

19. Paul G, Bataille F, Obermeier F, et al. Analysis of intestinal haem-oxygenase-1 (HO-1) in clinical and experimental colitis. Clin Exp Immunol 2005;140:547-555.

20. Hwang YP, Jeong HG. Mechanism of phytoestrogen puerarin-mediated cytoprotection following oxidative injury: estrogen receptor-dependent up-regulation of $\mathrm{PI}_{3} \mathrm{~K} /$ Akt and HO-1. Toxicol Appl Pharmacol 2008;233:371-381.

21. Yu HP, Choudhry MA, Shimizu T, et al. Mechanism of the salutary effects of flutamide on intestinal myeloper- 
oxidase activity following trauma-hemorrhage: up-regulation of estrogen receptor-\{beta\}-dependent HO-1. J Leukoc Biol 2006;79:277-284.

22. Chi X, Yao W, Xia H, et al. Elevation of HO-1 expression mitigates intestinal ischemia-reperfusion injury and restores tight junction function in a rat liver transplantation model. Oxid Med Cell Longev 2015;2015:986075.

23. Ahmed SM, Luo L, Namani A, Wang XJ, Tang X. Nrf2 signaling pathway: pivotal roles in inflammation. Biochim Biophys Acta Mol Basis Dis 2017;1863:585-597.

24. Park MN, Park JH, Paik HY, Lee SK. Insufficient sex description of cells supplied by commercial vendors. Am J Physiol Cell Physiol 2015;308:C578-C580.

25. DiDonato JA, Mercurio F, Karin M. NF-kappaB and the link between inflammation and cancer. Immunol Rev 2012;246:379-400.

26. Hertrampf T, Schmidt S, Laudenbach-Leschowsky U, Seibel J, Diel P. Tissue-specific modulation of cyclooxygenase-2 (Cox-2) expression in the uterus and the v. cava by estrogens and phytoestrogens. Mol Cell Endocrinol 2005;243:51-57.

27. Poligone B, Baldwin AS. Positive and negative regulation of NF-kappaB by COX-2: roles of different prostaglandins. J Biol Chem 2001;276:38658-38664.

28. Jaramillo MC, Zhang DD. The emerging role of the Nrf2-Keapı signaling pathway in cancer. Genes Dev
2013;27:2179-2191.

29. Khor TO, Huang MT, Kwon KH, Chan JY, Reddy BS, Kong AN. Nrf2-deficient mice have an increased susceptibility to dextran sulfate sodium-induced colitis. Cancer Res 2006;66:11580-11584.

30. Khor TO, Huang MT, Prawan A, et al. Increased susceptibility of Nrf2 knockout mice to colitis-associated colorectal cancer. Cancer Prev Res (Phila) 2008;1:187-191.

31. Torday JS. The sex difference in type II cell surfactant synthesis originates in the fibroblast in vitro. Exp Lung Res 1984;7:187-194.

32. Alsbeih G, Al-Meer RS, Al-Harbi N, et al. Gender bias in individual radiosensitivity and the association with genetic polymorphic variations. Radiother Oncol 2016; 119:236-243.

33. Vogel C, Marcotte EM. Insights into the regulation of protein abundance from proteomic and transcriptomic analyses. Nat Rev Genet 2012;13:227-232.

34. Chen CS, Tseng YT, Hsu YY, Lo YC. Nrf2-Keapı antioxidant defense and cell survival signaling are upregulated by 17beta-estradiol in homocysteine-treated dopaminergic $\mathrm{SH}_{-} \mathrm{SY}_{5} \mathrm{Y}$ cells. Neuroendocrinology 2013;97:232-241.

35. Tao S, Justiniano R, Zhang DD, Wondrak GT. The Nrf2-inducers tanshinone I and dihydrotanshinone protect human skin cells and reconstructed human skin against solar simulated UV. Redox Biol 2013;1:532-541. 